\title{
Phase Transformations in PZT Thin Films Prepared by Polymeric Chemical Method
}

\author{
Elton C. Lima, Eudes Borges Araújo* \\ Faculdade de Engenharia de Ilha Solteira, Departamento de Física e Química, UNESP_-Universidade Estadual Paulista, \\ Ilha Solteira, Brazil \\ Email: *eudes@dfq.feis.unesp.br
}

Received April 25, 2012; revised May 28, 2012; accepted June 8, 2012

\begin{abstract}
Lead zirconate titanate $\mathrm{Pb}\left(\mathrm{Zr}_{0.50} \mathrm{Ti}_{0.50}\right) \mathrm{O}_{3}$ (PZT) thin films were deposited by a polymeric chemical method on $\mathrm{Pt}(111)$ / $\mathrm{Ti} / \mathrm{SiO}_{2} / \mathrm{Si}$ substrates to understand the mechanisms of phase transformations in these films. PZT films pyrolyzed at temperatures higher than $350^{\circ} \mathrm{C}$ present a coexistence of pyrochlore and perovskite phases, while only perovskite phase is present in films pyrolyzed at temperatures lower than $300^{\circ} \mathrm{C}$. For films where the pyrochlore and perovskite phase coexists the amount of pyrochlore phase decreases from top surface to the bottom film-electrode interface and the PZT structure near top surface are Ti-rich compositions while near the bottom film-electrode interface the compositions are Zr-rich. For pyrochlore-free PZT thin film, a small (100) orientation tendency near the film-electrode interface was observed.
\end{abstract}

Keywords: PZT; Thin Films; Phase Transformation

\section{Introduction}

Over the past 50 years, the lead zirconate titanate $\mathrm{Pb}(\mathrm{Zr}, \mathrm{Ti}) \mathrm{O}_{3}$ (PZT) was probably one of the most studied ferroelectric materials due to their excellent physical properties [1]. In the ceramic form, PZT is well known for applications in piezoelectric, electrooptic and pyroelectric devices $[1,2]$. The great potential of the PZT system in the thin film form have been demonstrated along past years for applications in capacitors [3], micromechanical devices [4], nonvolatile ferroelectric random memories [5] and others. In contrast to new problems associated to downscaling of the solid-state electronics, some problems related to the synthesis of PZT thin films are periodically revisited providing activities to produce high performance devices.

The crystallization kinetics of PZT thin films is relatively well established for films prepared using physical or chemical deposition methods such as rf-sputtering [6], laser ablation [7] and sol-gel [8]. In general, the crystallization of PZT films using low temperature deposition techniques occurs from the amorphous structure that first transforms into an intermediate non-ferroelectric phase and then transform into the perovskite phase after an adequate pyrolysis and thermal annealing. Naturally, this transformation kinetic depends on the method used to prepare thin films. This undesirable non-ferroelectric

${ }^{*}$ Corresponding author. phase is often described as pyrochlore, sometimes also referred as $\mathrm{Pb}$-deficient fluorite phase [9]. The presence of this phase degrades the most important ferroelectric properties of the film and consequently must be avoided during the crystallization.

Until the late 20th century, some studies in PZT give emphasis to the analysis of pyrochlore to perovskite phase transformation in sol-gel derived thin films [10] and powders [11] while others studies advanced to understand the nucleation and growth mechanisms of PZT thin films [8,12]. Brooks et al. [12] have shown that the pyrolysis temperature and post-pyrolysis treatments are fundamental parameters to control the nucleation, growth and the microstructure to produce thin films with strong (111) or (100) texture. In addition, they have also shown that treatments in oxygen atmosphere always yield a significant amount of pyrochlore phase in the films that can be eliminated at annealing temperatures higher than $600^{\circ} \mathrm{C}$. The influence of the $\mathrm{Pb}$ excess and the $\mathrm{Zr} / \mathrm{Ti}$ composition was also studied as elements favorable to the formation of intermediate phases in PZT films prepared by metallo-organic decomposition process $[13,14]$. However, more recently the research on this subject has been focused on $\mathrm{Pb}$-loss and variations in $\mathrm{Zr} / \mathrm{Ti}$ cation fractions through the thickness of PZT and $(\mathrm{Pb}, \mathrm{La})(\mathrm{Zr}, \mathrm{Ti}) \mathrm{O}_{3}$ (PLZT) thin films $[15,16]$. However, not always the presence of pyrochlore phase can be interpreted as an inconvenience during the synthesis of thin films. The 
formation of a Pb-deficient fluorite phase in ultrathin films with thicknesses lower that $50 \mathrm{~nm}$ is beneficial to minimize electrode interactions and then use an adequate post-crystallization annealing step to produce a singlephase perovskite film with excellent electrical properties, as shown by Brennecka et al. in a recent work [17]. Very recent studies on the pyrochlore phase transformation in PLZT thin films demonstrate that the subject remains not completely understood [18].

Among the above-cited methods, PZT thin films have been also prepared by a hybrid chemical method based on Pechini [19] method to produce a polymeric resin from oxide precursors [20]. Although different studies were conducted on PZT films produced by this polymeric chemical method, up to now the kinetics of formation and suppression of the pyrochlore phase in these films was not yet systematically studied. Thus, the goal of the present work is to report the phase transformations and stabilization of the perovskite phase in PZT thin films prepared by the polymeric chemical method.

\section{Experimental}

PZT thin films with $\mathrm{Pb}\left(\mathrm{Zr}_{0.50} \mathrm{Ti}_{0.50}\right) \mathrm{O}_{3}$ nominal composition, including a $\mathrm{PbO}$ excess of $10 \mathrm{~mol} \%$, were prepared using a chemical polymeric method described elsewhere [20]. The general idea of the method is to prepare a polymeric resin according to the Pechini $[19,21]$ method and deposit it onto a substrate. Heating of the resin in air causes a breakdown of the polymer. Subsequently, the ions are oxidized to form the desired crystalline phases.

Initially, the films of polymer were deposited at room temperature on $\mathrm{Pt}(111) / \mathrm{Ti} / \mathrm{SiO}_{2} / \mathrm{Si}$ substrates by spin coating at $4000 \mathrm{rpm}$ for 30 seconds. To remove solvents and organics, each deposited layer was pyrolyzed in an electric furnace at temperatures of from $150^{\circ} \mathrm{C}$ to $450^{\circ} \mathrm{C}$ for 30 minutes. To increase the film thickness, this procedure was repeated from two up to six layers, each deposition receiving the above-mentioned thermal annealing. Finally, the films were crystallized at $700^{\circ} \mathrm{C}$ for $1 \mathrm{~h}$. Cross sections of the films were observed by a field emission scanning electron microscopy (JEOL JSM 6330F). The thicknesses of the films were $700 \mathrm{~nm}$ in average.

X-ray diffraction (XRD) was performed in $\theta-2 \theta$ configuration using a Rigaku Ultima IV diffractometer with $\mathrm{CuK}_{\alpha}(1.5406 \AA)$ radiation with a thin film attachment to study the structure of the films. The XRD measurements were performed at room temperature in step scan mode using the glancing incidence configuration at a fix $\theta$ angle from $0.5^{\circ}$ to $7^{\circ}$ and scanning the $2 \theta$ angle from $20^{\circ}$ to $60^{\circ}$. The structure in depth profile of pyrochlore-free PZT film was studied using Rietveld refinements [22]. Thus, the XRD patterns recorded at different glancing $\theta$ angles were inputted into the GSAS [23] structure re- finement code under the EXPGUI [24] interface. Peak profiles were fitted using the Thompson-Cox-Hastings [25] pseudo-Voigt function while a sixth-order polynomial was used to fit the background. The refinements were carried out considering a single tetragonal phase with P4 mm space group.

Williamson-Hall [26] analysis were applied to calculate the microstrain $(\Delta d / d)$ and crystallite size in depth profile of the pyrochlore-free PZT film from XRD data according to $\Gamma \cos \theta=\lambda / D+(\Delta d / d) 4 \operatorname{sen} \theta$, where $d$ is the lattice spacing, $\Gamma$ is the full width half maximum (FWHM) value due to peak broadening, $\lambda$ is the wavelength, $\theta$ is the Bragg angle, and $D$ is the average grain size, respectively [27]. For instrumental corrections, a standard $\mathrm{LaB}_{6}$ sample with a primitive cubic structure was used.

\section{Results and Discussion}

Figure 1(a) shows XRD profiles of PZT thin films prepared under different pyrolysis temperature. In this figure, the indexed $(h k l)$ peaks were associated to the tetragonal phase of the PZT, while both (222) and (400) peaks at $2 \theta$ $=29.8^{\circ}$ and $35.0^{\circ}$ were attributed to the pyrochlore phase. The XRD profiles of the PZT films pyrolyzed between $350^{\circ} \mathrm{C}$ and $450^{\circ} \mathrm{C}$ shows a coexistence of pyrochlore and perovskite phases, while for films pyrolyzed at $150^{\circ} \mathrm{C}$ and $300^{\circ} \mathrm{C}$ only peaks associated to the perovskite phase were observed. The presence of the (222) and (400) reflections in Figure 1(a) suggest a pyrochlore type phase of the $\mathrm{Pb}_{2} \mathrm{Ti}_{2} \mathrm{O}_{6}$ structure, with the possibility that $\mathrm{Zr}$ ions are able to substitute for $\mathrm{Ti}$ ions in the pyrochlore structure to form a more realistic metastable $\mathrm{Pb}_{2}\left(\mathrm{Zr}_{1-\mathrm{x}} \mathrm{Ti}_{\mathrm{x}}\right)_{2} \mathrm{O}_{6}$ structure [12]. In the literature, there are several reports on the possible composition of the pyrochlore phase for PZT films prepared by sol-gel route [10-12]. In general, these studies were centered on $\mathrm{Pb}\left(\mathrm{Zr}_{0.53} \mathrm{Ti}_{0.47}\right) \mathrm{O}_{3}$ film composition for historical reasons and there is a consensus that above mentioned (222) and (400) reflections were attributed to the pyrochlore $\mathrm{Pb}_{2}\left(\mathrm{Zr}_{0.53} \mathrm{Ti}_{047}\right)_{2} \mathrm{O}_{6}$ phase. Our study, however, was centered on the $\mathrm{Pb}\left(\mathrm{Zr}_{0.50} \mathrm{Ti}_{0.50}\right) \mathrm{O}_{3}$ composition and this proposal offers some advantage to interpret the formation of pyrochlore phase in our films, as we shall see in the next paragraph.

Figure 1(b) shows more closely the evolution of the (002) and (200) peaks in XRD patters of the PZT films for different pyrolysis temperatures. For films pyrolyzed at $400^{\circ} \mathrm{C}$ and $450^{\circ} \mathrm{C}$ a clear structure of two peaks was observed at $2 \theta=44.7^{\circ}$ and $45.9^{\circ}$. However, a structure of a single broad peak was observed in XRD patters of the films pyrolyzed at temperatures below $300^{\circ} \mathrm{C}$. These observed changes gives us important qualitative information about structure of the PZT films and indirectly infers about the dynamic of the pyrochlore phase and its probably composition. 


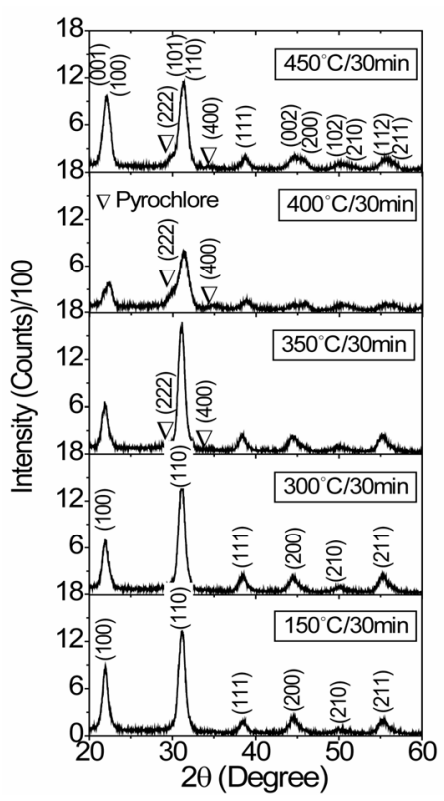

(a)

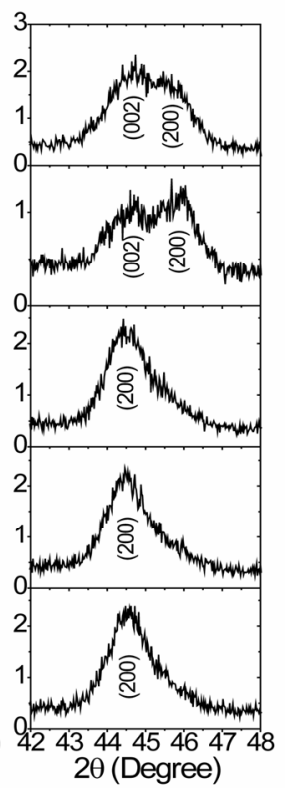

(b)
Figure 1. (a) XRD profiles of PZT thin films crystallized at $7_{00}^{\circ} \mathrm{C}$ for 1 hour on $\mathrm{Pt}(111) / \mathrm{Ti} / \mathrm{SiO}_{2} / \mathrm{Si}$ substrates and pyrolyzed at different temperatures. All XRD patterns were recorded at a fix glancing angle $\theta=7^{\circ}$; (b) XRD profiles around the (002) and (200) reflections for PZT films.

For PZT ceramics, the splitting of $(00 l)$ and $(h 00)$ reflections in XRD patterns with $\mathrm{Zr} / \mathrm{Ti}$ ratio decreasing is clear evidence that symmetry changes from rhombohedral to tetragonal [27]. The substitution of $\mathrm{Zr}$ ions for Ti ions in $\mathrm{PbTiO}_{3}$ leads to a change in the structure from tetragonal to rhombohedral symmetry and vice versa for substitution of $\mathrm{Ti}$ ions for $\mathrm{Zr}$ ions. As the splitting of $(00 l)$ and $(h 00)$ reflections is more evident for higher $2 \theta$ angles in XRD pattern, we focus our discussions on the (002) and (200) reflections. In other words, PZT rhombohedral compositions (Zr-rich) exhibit a single (200) reflection while tetragonal compositions (Ti-rich) exhibit double (002) and (200) reflections in XRD pattern (see Figure 2 in Ref. [27]). Supported by these discussions it is clear that PZT films present distinct structure depending on pyrolysis temperature.

The splitting of (002) and (200) reflections in Figure 1(b) for PZT films pyrolyzed at $400^{\circ} \mathrm{C}$ and $450^{\circ} \mathrm{C}$ clearly indicates a shift toward the tetragonal side in the composition-temperature phase diagram of the PZT system [1]. This implies a Ti-rich PZT composition $(\mathrm{Zr} / \mathrm{Ti}<1)$ in comparison to the nominal $\mathrm{Pb}\left(\mathrm{Zr}_{0.50} \mathrm{Ti}_{0.50}\right) \mathrm{O}_{3}$ composition $(\mathrm{Zr} / \mathrm{Ti}=1)$, which would enrich the pyrochlore phase and reduce the perovskite phase in $\mathrm{Zr}$ ions. These results strongly indicate that the growth of a $\mathrm{Zr}$-rich pyrochlore phase $\mathrm{Pb}_{2}\left(\mathrm{Zr}_{1-x} \mathrm{Ti}_{x}\right)_{2} \mathrm{O}_{6}(\mathrm{Zr} / \mathrm{Ti}>1)$ is more energetically favorable for films pyrolyzed at $400^{\circ} \mathrm{C}$ and $450^{\circ} \mathrm{C}$. However, a result slightly different was observed in Figure 1(b) for PZT films pyrolyzed at $150^{\circ} \mathrm{C}, 300^{\circ} \mathrm{C}$ and $350^{\circ} \mathrm{C}$. For these films, the structure of a single broad (200) peak was observed around $2 \theta=45.5^{\circ}$, which is an expected characteristic of the tetragonal phase for the studied PZT with $\mathrm{Zr} / \mathrm{Ti}=1$. While PZT films pyrolyzed at $150^{\circ} \mathrm{C}$ and $300^{\circ} \mathrm{C}$ are pyrochlore free, the film pyrolyzed at $350^{\circ} \mathrm{C}$ presents a small amount of pyrochlore phase, as indicated in Figure 1(a). In this case, we can infer the growth of a pyrochlore phase with $\mathrm{Zr} / \mathrm{Ti} \cong 1$ in this film.

A structural study was conducted in depth profile of a PZT film, where the pyrochlore and perovskite phases coexist. Figure 2 shows XRD profiles for different glancing angle $\theta$ of PZT thin film pyrolyzed at $450^{\circ} \mathrm{C}$ for $30 \mathrm{~min}$. The evolution of the (110) perovskite and (222) and (400) pyrochlore reflections as a function of glancing angle $\theta$ is shown in Figure 2(a). In this figure, the (222) and (400) reflections are present for glancing angle $2^{\circ} \leq$ $\theta \leq 7^{\circ}$ and disappear for $\theta$ smaller than $1^{\circ}$. It is an indicative that the pyrochlore phase crystallizes predominantly near the film-electrode bottom interface and disappears near the film surface. In other words, the XRD patterns in Figure 2(a) shows a mixture of pyrochlore and perovskite phase over film depth, while the film surface is a

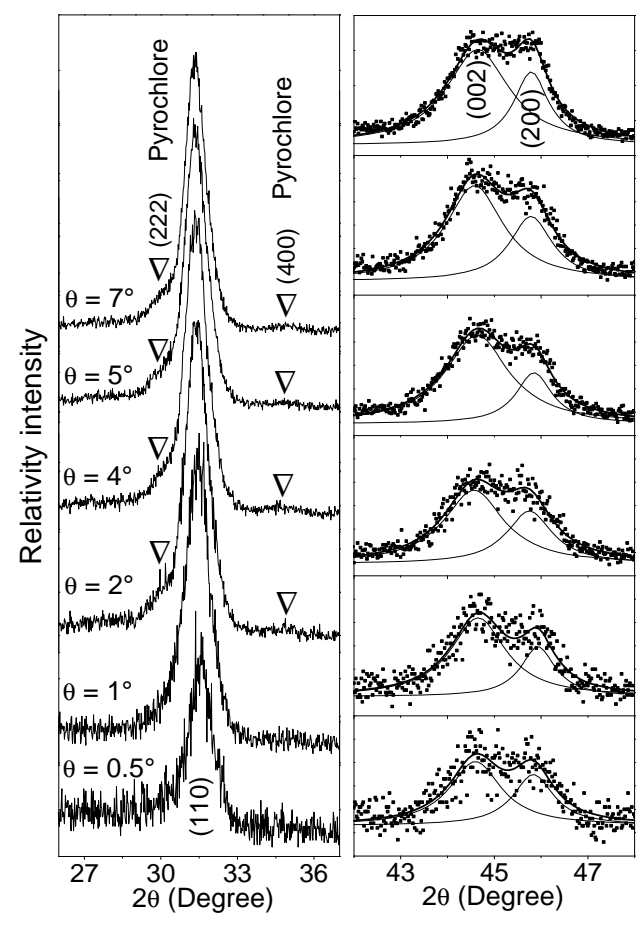

(a)

(b)

Figure 2. XRD profiles for different glancing angle $\theta$ of PZT thin film crystallized at $700^{\circ} \mathrm{C}$ for 1 hour on $\mathrm{Pt}(111) / \mathrm{Ti} /$ $\mathrm{SiO}_{2} / \mathrm{Si}$ substrate and pyrolyzed at $450^{\circ} \mathrm{C}$ for $30 \mathrm{~min}$. (a) Evolution of the XRD profiles of the (222), (400) and (110) reflections; (b) Fitting on (002) and (200) XRD peaks using two lorentzian functions, where dots are experimental data while continuous lines represent the lorentzian functions and fitting profiles. 
pyrochlore-free region. Figure 2(b) shows the behavior of the (002) and (200) reflections for different glancing angle $\theta$, where points are experimental data and lines are theoretical profiles fitted using a couple of lorentzian functions. At first glance, there is no substantial change in shape and position of both peaks, but a compositional gradient is observed for PZT in the depth profile, as will be shown next.

The difference $\Delta \theta=2 \theta_{(200)}-2 \theta_{(002)}$ for both (002) and (200) reflections from fitting in Figure 2(b) is shown in Figure 3(a) as a function of glancing incidence $\theta$ angle, while the $2 \theta$ positions dependence for (110), (100) and (001) reflections is shown in Figure 3(b). The observed decrease in $\Delta \theta$ with increasing the glancing $\theta$ angle is an indicative of a compositional gradient for PZT in the depth profile. In this case, $\mathrm{Zr} / \mathrm{Ti}$ ratio near the film surface is lower than same ratio for PZT composition near the bottom film-electrode interface. This means that PZT compositions near the film surface are more Ti-rich than compositions near the film-electrode interface. The shift on the $2 \theta$ peak position for $(110),(100)$ and (001) reflections shown in Figure 3(b) confirms the Ti-rich composition near the bottom film-electrode interface and $\mathrm{Ti}$ poor near the film surface.

The pyrochlore phase transformations in PZT thin films have been studied by several researchers in recent

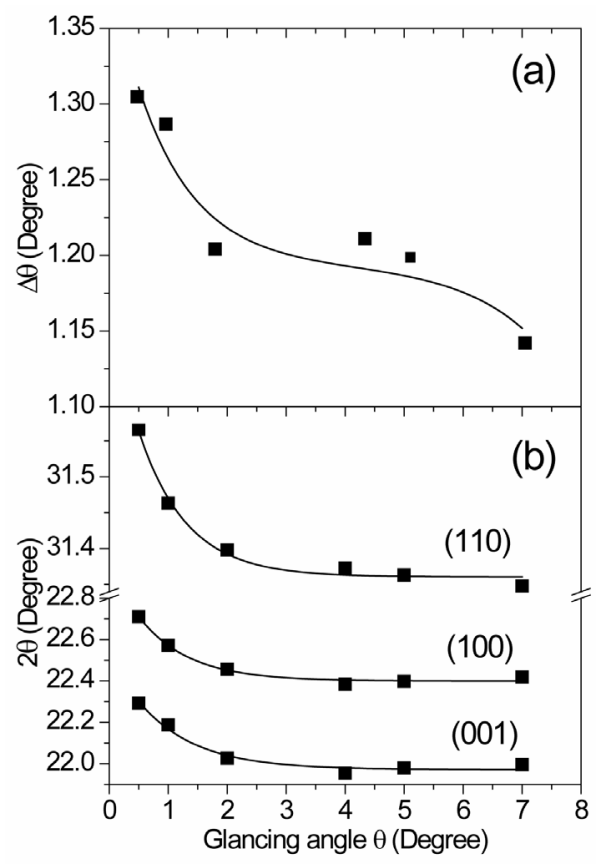

Figure 3. (a) Behavior of difference $\Delta \theta=2 \theta_{(200)}-2 \theta_{(002)}$ in $2 \theta$ peak positions for both $(002)$ and $(200)$ reflections as a function of XRD glancing angle $\theta$ for PZT film pyrolyzed at $450^{\circ} \mathrm{C}$ for $30 \mathrm{~min}$. These data were recorded from fitting in Figure 2(b). (b) Graphic representation of $2 \theta$ position of the (001), (100) and (110) reflections as a function of glancing angle $\theta$, based on same XRD pattern shown in Figure 1(a). years using X-ray diffraction [28] and combined techniques such as transmission-electron microscopy $[8,10]$. For PZT films prepared by rapid thermal processing, these studies have demonstrated that the perovskite phase nucleates first at the bottom electrode and crystallizes a mixture of perovskite and pyrochlore phases with a surface of pyrochlore phase. In general, it is observed that perovskite phase grows from the bottom electrode and a pure pyrochlore phase covering the perovskite phase [8] or a large packet of pyrochlore phase penetrates through the film to the substrate [16]. Studies on the compositional gradients through the thickness of PZT thin films prepared by sol-gel shows a tendency of high $\mathrm{Zr}$ content in the film surface and high Ti content near the bottom film-electrode interface [15]. In the present work, however, results suggest that the pyrochlore phase grows near the bottom electrode meanwhile a perovskite phase grows on the pyrochlore leading to a pyrochlore-free at the film surface.

Figure 4 shows the observed and calculated XRD profiles for pyrochlore-free PZT thin film pyrolyzed at $300^{\circ} \mathrm{C}$ for $30 \mathrm{~min}$ and crystallized at $700^{\circ} \mathrm{C}$ for 1 hour. Inset in this figure shows a scanning electron microscopy cross section image for this film. The cross section image shows a dense microstructure with a uniform grain size distribution. On average, the grain size and thickness were $75 \mathrm{~nm}$ and $710 \mathrm{~nm}$, respectively. All indexed peaks in XRD pattern were attributed to tetragonal phase. For

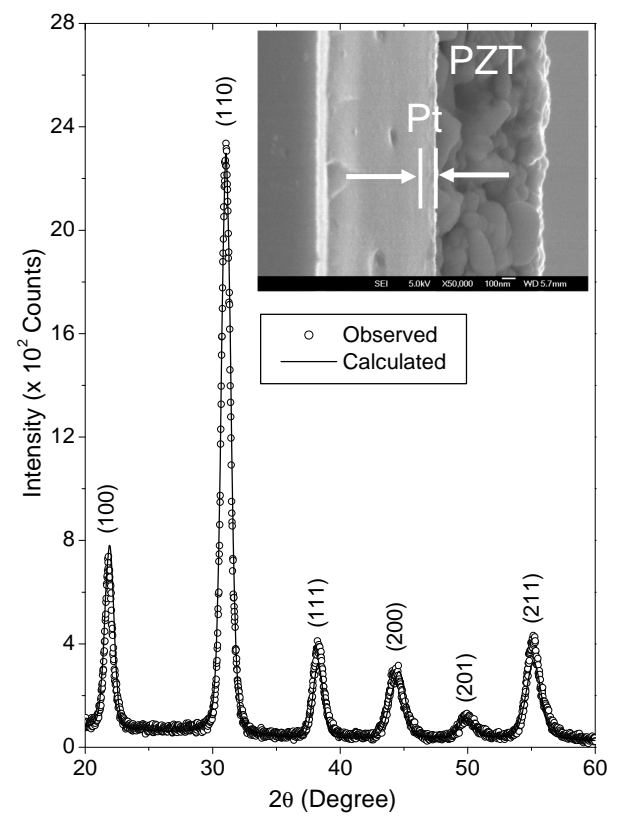

Figure 4. The observed (dots) and calculated (lines) XRD profiles of the $\mathrm{PZT}$ thin film deposited on $\mathrm{Pt}(111) / \mathrm{Ti} / \mathrm{SiO}_{2} / \mathrm{Si}$ substrate, pyrolyzed at $300^{\circ} \mathrm{C}$ for $30 \mathrm{~min}$ and crystallized at $700^{\circ} \mathrm{C}$ for 1 hour. The XRD profile was recorded at $6^{\circ}$ glancing angle. The inset shows a SEM cross section image of this film. 
all Rietveld refinements, we adopt the same convention as that used by Noheda et al. [29]. In the tetragonal phase, the $\mathrm{Pb}^{2+}$ ions occupies sites at $(0,0,0), \mathrm{Ti}^{4+} / \mathrm{Zr}^{4+}$ and $O_{I}^{2-}$ occupy sites $(1 / 2,1 / 2, z)$, and $O_{I I}^{2-}$ occupy sites at $(1 / 2$, $0, z)$. For the XRD recorded at glancing angle $\theta=7^{\circ}$, the obtained R-factors [30] weighted profile $\mathrm{wR}_{\mathrm{p}}$, the statistically expected $\mathrm{R}_{\exp }$ and the goodness-of-fit indices $\chi^{2}$ were respectively $14.24 \%, 8.11 \%$ and 3.1 . The refined positions were $z=0.457(3) \AA$ for $\mathrm{Ti}^{4+} / \mathrm{Zr}^{4+}$, $z=0.092(5) \AA$ for $O_{I}^{2-}$ and $z=0.610(4) \AA$ for $O_{I I}^{2-}$ ions. The calculated lattice parameters were $a=b=4.069(7) \AA$ and $c=4.129(1) \AA$. Based on the calculated lattice constants the obtained tetragonality factor was $c / a=1.015$ for this film. This factor is very close the value for bulk PZT reported in the literature $(c / a=1.029)$ for the same composition [31]. The $c / a$ factor for PZT films studied in the present work remains almost constant over bulk but decreases slightly to $c / a=$ 1.011 around the film surface (glancing angle $\theta=2^{\circ}$ ).

Figure 5 shows some selected structural properties from Rietveld refinements on the XRD patterns recorded as a function of glancing $\theta$ angle for PZT thin film pyrolyzed at $300^{\circ} \mathrm{C}$ for $30 \mathrm{~min}$ and crystallized at $700^{\circ} \mathrm{C}$ for 1 hour. Figures 5(a) and 5(b) shows respectively the depth profile of microstrain $(\Delta d / d)$ and the crystallite size (D) for pyrochlore-free PZT thin film. Results demonstrated a non-uniform microstrain and crystallite size along the film thickness. The obtained microstrain $(0.56 \%$ to $0.79 \%)$ for the studied film were similar to values reported in the literature for polycrystalline Nd-modified PZT films [32] and slightly larger than values reported for (100)-oriented PZT films prepared by rf-sputtering technique $(\sim 0.15 \%$ for film with $100 \mathrm{~nm}$ in thickness) [33]. The values obtained for the crystallite size $(18-41 \mathrm{~nm})$ were lower than those values reported in the literature $(\sim 90 \mathrm{~nm}$ for film with $270 \mathrm{~nm}$ in thickness) for PZT films prepared by rf-sputtering [34].

The strain in ferroelectric thin films is generally attributed to the sum of the elastic strain due to the lattice difference between the film and the substrate, the thermal strain as the substrate imposes its thermal evolution onto the film and the spontaneous transformation strain linked to the phase transitions [35]. In the specific case of this work, results indicate a microstrain relaxation from the bottom film-electrode interface to the top surface. Furthermore, the results show that close to the film-electrode interface the crystallite size are slightly larger than near the film surface.

The behavior $\mathrm{I}(100) / \mathrm{I}(110)$ ratio between maximum peak intensities as a function of glancing incidence $\theta$ angle is shown in Figure 5(c). The texture of the film over its thickness could be monitored by the I(100)/I(110) ratio behavior. By increasing the $\theta$ angle, it is expected that the $\mathrm{I}(100) / \mathrm{I}(110)$ ratio should be constant for a

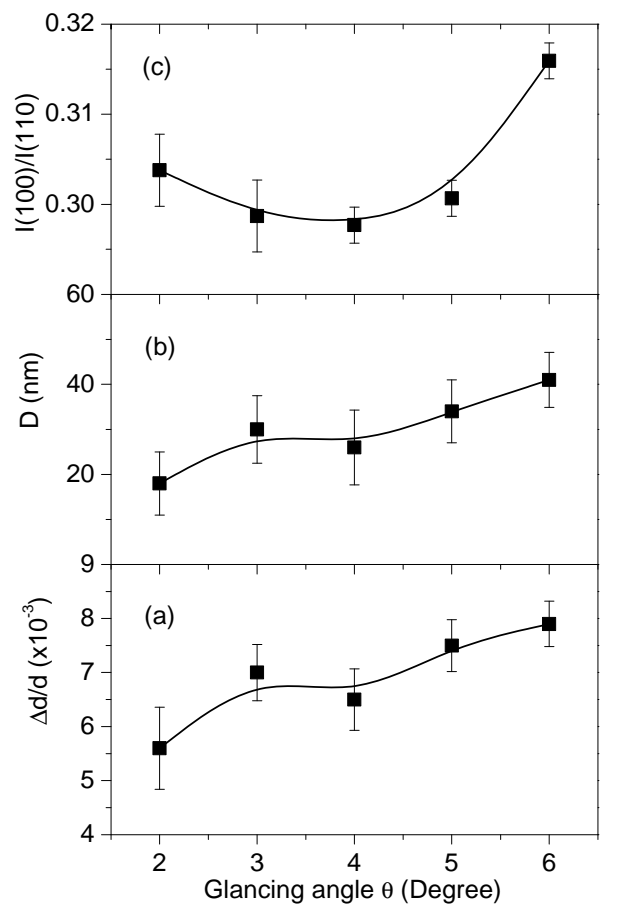

Figure 5. (a) Microstrain, (b) crystallite size and (c) I(100)/ I(110) ratio as a function of XRD glancing angle $\theta$ for pyrochlore-free $\mathrm{PZT}$ thin film deposited on $\mathrm{Pt}(111) / \mathrm{Ti} / \mathrm{SiO}_{2} / \mathrm{Si}$ substrate, pyrolyzed at $300^{\circ} \mathrm{C}$ for $30 \mathrm{~min}$ and crystallized at $700^{\circ} \mathrm{C}$ for 1 hour.

homogeneous and stress-free structure along the film thickness. The $\mathrm{I}(100) / \mathrm{I}(110)$ ratio remains almost unchanged for $\theta$ smaller than $5^{\circ}$ but increases by $5 \%$ for $\theta=$ $6^{\circ}$. This increasing is a result of the texture changes in the film depth and indicates a small (100) orientation tendency near the film-electrode interface.

The texture for PZT thin films is generally influenced by several factors such as pyrolysis temperature [36] or seeding layers [37] introduced during processing, leading to (111) or (100) PZT orientation of the film grown on (111) Pt metallic electrode. The slight tendency to (100) texture observed in the present work at the film-electrode interface indicates that the nucleation of the first layer is not dominated by lattice matching between (111) PZT and (111) Pt metallic electrode. As the film was prepared by several coatings, a small amount of nuclei of (100) orientation is formed at the film-electrode interface during pyrolysis. These nuclei became unstable on the next deposited layers due to lower interfacial energy at the film-electrode interface. Consequently, a randomly oriented film grew on the partially (100) oriented layer.

\section{Conclusion}

In conclusion, the transformation of the pyrochlore phase into the perovskite phase along the $\mathrm{Pb}\left(\mathrm{Zr}_{0.50} \mathrm{Ti}_{0.50}\right) \mathrm{O}_{3}$ thin films prepared by polymeric precursor method were stud- 
ied. The pyrochlore phase grew in films pyrolyzed at temperatures higher than $350^{\circ} \mathrm{C}$ and disappears in films pyrolyzed at temperatures lower than $300^{\circ} \mathrm{C}$. Results indicates that for films where the pyrochlore and perovskite phase coexists the amount of pyrochlore phase decreases from top surface to the bottom film-electrode interface meanwhile the PZT structure changes from Ti-rich compositions near top surface to Zr-rich compositions near the film-electrode interface. For pyrochlorefree PZT thin film, the texture changes along the thickness leads to a small (100) orientation tendency near the film-electrode interface.

\section{Acknowledgements}

We would like to express our gratitude to Brazilian agencies FAPESP (Processes: 2007/08534-3 and 2010/ 16504-0) and CNPq (Grant 307607/2009-7) for the financial support. The authors wish to thank the use of the SEM/FEG electron microscope at the LME/LNLS, Campinas (Brazil).

\section{REFERENCES}

[1] B. Jaffe, W. R. Cook and H. Jaffe, "Piezoelectric Ceramics," Academic Press, New York, 1971, pp. 135183.

[2] G. H. Heartling, "Electro-Optic Ceramics and Devices," In: L. M. Levinson, Electronic Ceramics, Marcel and Dekker, New York, 1988.

[3] M. Miyake, J. F. Scott, X. J. Lou, F. D. Morrison, T. Nonaka, S. Motoyama, T. Tatsuta and O. Tsuji, "Submicron Three-Dimensional Trenched Electrodes and Capacitors for DRAMs and FRAMs: Fabrication and Electrical Testing," Journal of Applied Physics, Vol. 104, No. 6, 2008, Article ID: 064112. doi:10.1063/1.2981197

[4] C. H. Ahn, K. M. Rabe and J.-M. Triscone, "Ferroelectricity at the Nanoscale: Local Polarization in Oxide Thin Films and Heterostructures," Science, Vol. 303, No. 5657, 2004, pp. 488-491. doi:10.1126/science. 1092508

[5] J. F. Scott and C. A. P. de Araujo, "Ferroelectric Memories," Science, Vol. 246, No. 4936, 1989, pp. 1400-1405. doi:10.1126/science.246.4936.1400

[6] K. Sreenivas and M. Sayer, P. Garret, "Properties of D.C. Magnetron-Sputtered Lead Zirconate Titanate Thin Films," Thin Solid Films, Vol. 172, No. 2, 1989, pp. 251267. doi:10.1016/0040-6090(89)90653-6

[7] O. Auciello, L. Mantese, J. Duarte, X. Chen, S. H. Rou, A. I. Kingon, A. F. Schreiner and A. R. Krauss, "Synthesis and Characterization of $\mathrm{Pb}\left(\mathrm{Zr}_{x} \mathrm{Ti}_{1-x}\right) \mathrm{O}_{3}$ Thin Films Produced by an Automated Laser Ablation Deposition Technique," Journal of Applied Physics, Vol. 73, No. 10, 1993, p. 5197. doi:10.1063/1.353746

[8] I. M. Reaney, D. V. Taylor and K. G. Brooks, "Ferroelectric PZT Thin Films by Sol-Gel Deposition," Journal of Sol-Gel Science and Technology, Vol. 13, No. 1-3, 1998, pp. 813-820. doi:10.1023/A:1008690316261
[9] A. P. Wilkinson, J. S. Speck, A. K. Cheetham, S. Natarajan and J. M. Thomas, "In Situ X-Ray Diffraction Study of Crystallization Kinetics in $\mathrm{PbZr}_{1-x} \mathrm{Ti}_{x} \mathrm{O}_{3}$, (PZT, $x=0.0$, 0.55, 1.0)," Chemistry of Materials, Vol. 6, No. 6, 1994, pp. 750-754. doi:10.1021/cm00042a009

[10] C. K. Kwok and S. B. Desu, "Pyrochlore to Perovskite Phase Transformation in Sol-Gel Derived Lead-ZirconateTitanate Thin Films," Applied Physics Letters, Vol. 60, No. 12, 1992, p. 1430. doi:10.1063/1.107312

[11] V. S. Tiwari, A. Kumar, V. K. Wadhawan and D. Pandey, "Kinetics of Formation of the Pyrochlore and Perovskite Phases in Sol-Gel Derived Lead Zirconate Titanate Powder," Journal of Materials Research, Vol. 13, No. 8, 1998, pp. 2170-2173. doi:10.1557/JMR.1998.0303

[12] K. G. Brooks, I. M. Reaney, R. Klissurska, Y. Huang, L. Bursill and N. Setter, "Orientation of Rapid Thermally Annealed Lead-Zirconate-Titanate Thin-Films on (111) Pt Substrates," Journal of Materials Research, Vol. 9, No. 10, 1994, pp. 2540-2553. doi:10.1557/JMR.1994.2540

[13] S. Y. Chen and I. W. Chen, "Temperature-Time Texture Transition of $\mathrm{Pb}\left(\mathrm{Zr}_{1-x} \mathrm{Ti}_{x}\right) \mathrm{O}_{3}$ Thin Films: I, Role of $\mathrm{Pb}$ Rich Intermediate Phases," Journal of the American Ceramic Society, Vol. 77, No. 9, 1994, pp. 2332-2336. doi:10.1111/j.1151-2916.1994.tb04602.x

[14] S. Y. Chen and I. W. Chen, "Temperature-Time Texture Transition of $\mathrm{Pb}\left(\mathrm{Zr}_{1-x} \mathrm{Ti}_{x}\right) \mathrm{O}_{3}$ Thin Films: II, Heat Treatment and Compositional Effects," Journal of the American Ceramic Society, Vol. 77, No. 9, 1994, 2337-2344. doi:10.1111/j.1151-2916.1994.tb04603.x

[15] A. Etin, G. E. Shter, S. Baltianski, G. S. Grader and G. M. Reisner, "Controlled Elemental Depth Profile in SolGel-Derived PZT Films," Journal of the American Ceramic Society, Vol. 89, No. 8, 2006, pp. 2387-2393. doi:10.1111/j.1551-2916.2006.01078.x

[16] C. M. Parish, G. L. Brennecka, B. A. Tuttle and L. N. Brewer, "Quantitative X-Ray Spectrum Imaging of Lead Lanthanum Zirconate Titanate PLZT Thin-Films," Journal of the American Ceramic Society, Vol. 91, No. 11, 2008, pp. 3690-3697. doi:10.1111/j.1551-2916.2008.02708.x

[17] G. L. Brennecka, C. M. Parish, B. A. Tuttle, L. N. Brewer and M. A. Rodriguez, "Reversibility of the Perovskiteto-Fluorite Phase Transformation in Lead-Based Thin and Ultrathin Films," Advanced Materials, Vol. 20, No. 8, 2008, pp. 1407-1411. doi:10.1002/adma.200702442

[18] K. Nittala, G. L. Brennecka, B. A. Tuttle and J. L. Jones, "Phase Evolution in Solution Deposited Pb-Deficient PLZT Thin Films," Journal of Materials Science, Vol. 46, No. 7, 2011, pp. 2148-2154. doi:10.1007/s10853-010-5051-x

[19] M. Pechini, "Method of Preparing Lead and Alkaline Earth Titanates and Niobates and Coating Method Using the Same to Form a Capacitor," US Patent No. 3330697, 1967.

[20] E. B. Araújo and J. A. Eiras, "PZT Thin Films Obtained from Oxide Precursors," Journal of Materials Science Letters, Vol. 17, No. 10, 1998, pp. 833-835. doi:10.1023/A:1006698708601

[21] P. A. Lessing, "Mixed-Cation Oxide Powders via Poly- 
meric Precursors," Ceramic Bulletin, Vol. 68, No. 5, 1989 , pp. 1002-1007.

[22] H. M. Rietveld, "Line Profiles of Neutron Powder-Diffraction Peaks for Structure Refinement," Acta Crystallographica, Vol. 22, No. 1, 1967, pp. 151-152. doi:10.1107/S0365110X67000234

[23] A. C. Larson and R. B. Von Dreele, "Los Alamos National Laboratory Report LAUR 86," 1994.

[24] B. H. Toby, "EXPGUI, a Graphical User Interface for GSAS," Journal of Applied Crystallography, Vol. 34, No. 2, 2001, pp. 210-213. doi:10.1107/S0021889801002242

[25] P. Thompson, D. E. Cox and J. B. Hastings, "Rietveld Refinement of Debye-Scherrer Synchrotron X-Ray Data from $\mathrm{Al}_{2} \mathrm{O}_{3}$," Journal of Applied Crystallography, Vol. 20, No. 2, 1987, pp. 79-83. doi:10.1107/S0021889887087090

[26] G. K. Williamson and W. H. Hall, "X-Ray Line Broadening from Filed Aluminium and Wolfram," Acta Mettallurgica, Vol. 1, No. 1, 1953, pp. 22-31. doi:10.1016/0001-6160(53)90006-6

[27] R. Lal, R. Krishnan and P. Ramakrishnan, "Transition between Tetragonal and Rhombohedral Phases of PZT Ceramics Prepared from Spray-Dried Powders," British Ceramic Transactions and Journal, Vol. 87, No. 3, 1988, pp. 99-102.

[28] E. M. Griswold, L. Weaver, M. Sayer and I. D. Calder, "Phase-Transformations in Rapid Thermal Processed Lead-Zirconate-Titanate," Journal of Materials Research, Vol. 10, No. 12, 1995, pp. 3149-3159. doi:10.1557/JMR.1995.3149

[29] B. Noheda, J. A. Gonzalo, L. E. Cross, R. Guo, S. E. Park, D. E. Cox and G. Shirane, "Tetragonal-to-Monoclinic Phase Transition in a Ferroelectric Perovskite: The Structure of $\mathrm{PbZr}_{0.52} \mathrm{Ti}_{0.48} \mathrm{O}_{3}$," Physical Review B, Vol. 61, No. 13, 2000, pp. 8687-8695. doi:10.1103/PhysRevB.61.8687

[30] L. B. McCusker, R. B. Von Dreele, D. E. Cox, D. Louër, and P. Scardi, "Rietveld Refinement Guidelines," Journal of Applied Crystallography, Vol. 32, No. 1, 1999, pp. 36-

\section{0. doi:10.1107/S0021889898009856}

[31] B. Noheda, D. E. Cox, G. Shirane, R. Guo, B. Jones and L. E. Cross, "Stability of the Monoclinic Phase in the Ferroelectric Perovskite $\mathrm{PbZr}_{1-x} \mathrm{Ti}_{x} \mathrm{O}_{3}$," Physical Review $B$, Vol. 63, No. 1, 2001, Article ID: 014103. doi:10.1103/PhysRevB.63.014103

[32] J. Lappalainen, V. Lantto, J. Frantti and J. Hiltunen, "XRay Diffraction and Raman Investigations of Thickness Dependent Stress Effects on $\mathrm{Pb}\left(\mathrm{Zr}_{x} \mathrm{Ti}_{1-x}\right) \mathrm{O}_{3}$ Thin Films," Applied Physics Letters, Vol. 88, No. 25, 2006, Article ID: 252901. doi:10.1063/1.2216895

[33] D. Kwon, B. Kim, B. G. Kim and C. H. Chang, "Strain Relaxation and Formation of a-Domains for $\mathrm{PbZr}_{0.2} \mathrm{Ti}_{0.8} \mathrm{O}_{3}$ Thin Films Epitaxially Grown on $\mathrm{SrTiO}_{3}$ Substrates," Journal of Korean Physical Society, Vol. 55, No. 4, 2009, pp. L1327-L1330. doi:10.3938/jkps.55.1327

[34] X. Y. Wen, J. Yu, Y. B. Wang, W. L. Zhou, J. X. Gao, "Stress Analysis and Ferroelectric Properties of $\mathrm{Pb}$ $\left(\mathrm{Zr}_{0.52} \mathrm{Ti}_{0.48}\right)_{0.96} \mathrm{Nb}_{0.04} \mathrm{O}_{3}$ Thin Film Grown on Different Thickness of $\mathrm{BaPbO}_{3}$ Electrodes," Journal of Applied Physics, Vol. 108, No. 11, 2010, Article ID: 114103. doi:10.1063/1.3518516

[35] P. E. Janolin, "Strain on Ferroelectric Thin Films Example of $\mathrm{Pb}\left(\mathrm{Zr}_{1-x} \mathrm{Ti}_{x}\right) \mathrm{O}_{3}$," Journal of Materials Science, Vol. 44, No. 19, 2009, pp. 5025-5048. doi:10.1007/s10853-009-3553-1

[36] I. M. Reaney, K. Brooks, R. Klissurska, C. Pawlaczyk and N. Setter, "Use of Transmission Electron Microscopy for the Characterization of Rapid Thermally Annealed, Solution-Gel, Lead Zirconate Titanate Films," Journal of the American Ceramic Society, Vol. 77, No. 5, 1994, pp. 1209-1216. doi:10.1111/j.1151-2916.1994.tb05394.x

[37] W. Gong, J. F. Li, X. Chu, Z. Gui and L. Li, "Preparation and Characterization of Sol-Gel Derived (100)-Textured $\mathrm{Pb}(\mathrm{Zr}, \mathrm{Ti}) \mathrm{O}_{3}$ Thin Films: PbO Seeding Role in the Formation of Preferential Orientation," Acta Materialia, Vol. 52, No. 9, 2004, pp. 2787-2793. doi:10.1016/j.actamat.2004.02.025 